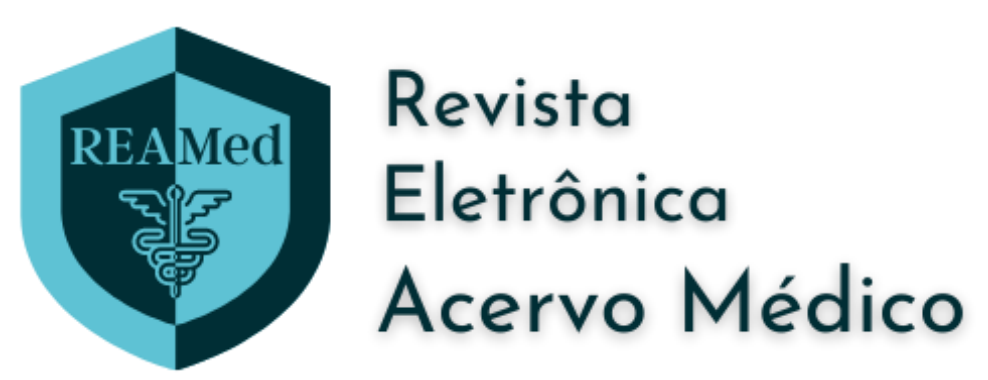

\title{
Aspectos radiográficos e tomográficos da infecção por SARS-CoV-2e suas complicações cardiopulmonares: um estudo de caso
}

\author{
Radiographic and tomographic aspects of SARS-Cov-2 infection and its cardiopulmonary \\ complications: a case study
}
Aspectos radiográficos y tomográficos de la infección por SARS-Cov-2 y sus complicaciones cardiopulmonares: un estudio de caso

Matheus Costa Leite ${ }^{1 *}$, Anna Clara Oliveira Santos ${ }^{1}$, Thaís Rosa da Silveira e Silva ${ }^{1}$, Mariana Barbosa Zica1 ${ }^{1}$, Ana Luiza Dumbá Castro Soares ${ }^{1}$, Thais Stefany Figueiredo Souza ${ }^{1}$, Maria Luisa Cardoso Oliveira ${ }^{2}$, Cecília Soares de Oliveira ${ }^{1}$, Ana Cláudia Zuba da Silva ${ }^{1}$, Renato Vilas Boas Antunes ${ }^{3}$.

\section{RESUMO}

Objetivo: Relatar o caso de uma paciente diagnosticada com COVID-19, com alterações típicas de imagem e com evolução a tromboembolismo pulmonar, relacionando os principais sinais e sintomas com as alterações nos exames de imagem, assim como as principais repercussões cardiorrespiratórias. Detalhamento do caso: Paciente feminina, 54 anos, hipertensa, vacinada com a primeira dose da vacina AstraZeneca® contra o SARS-CoV2, apresentou sintomas gripais e teste RT-PCR positivo, evoluindo com quadro de tosse persistente, dispneia progressiva e dessaturação. Durante o decorrer do quadro apresentou febre, dor to rácica em região mediastinal, hiposmia e hipogeusia. Como abordagem terapêutica foi necessário internação em regime hospitalar, oxigenoterapia suplementar de baixo fluxo, corticoide sistêmico, antibioticoterapia endovenosa e suporte respiratório, com melhora clínica e alta após 10 dias de internação. Radiografia Torácica ao nono dia de sintomas apresentou opacidades parenquimatosas de padrão interstício -alveolar, e Angiotomografia computadorizada de Artérias Pulmonares, realizada após 25 dias de sintomas demonstrou Tromboembolismo Pulmonar (TEP) extenso. Considerações finais: O relato reforça a importância de reconhecer as características, evolução e complicações cardiorrespiratórias da doença, compreendendo que os aspectos dos exames de imagem são heterogêneos entre os af etados. Dessa maneira realizar a melhor avaliação e conduta.

Palavras-chave: COVID-19, Tomografia computadorizada, Tromboembolismo pulmonar, Radiografia torácica.

\section{ABSTRACT}

Objective: To report the case of a patient diagnosed with COVID-19, with typical image changes and evolution to pulmonary thromboembolism, relating the main signs and symptoms with changes in imaging tests, as well as the main cardiorespiratory repercussions. Case details: Female patient, 54 years old, hypertensive, vaccinated with the first dose of AstraZeneca® vaccine against SARS-CoV2, presented flu-like symptoms and

${ }^{1}$ Centro Universitário FUNORTE, Montes Claros - MG. `E-mail: leite.mantheuscosta@gmail.com

2 Centro Universitário UNIFIPMOC, Montes Claros - MG.

${ }^{3}$ Clínica MEDIMAGEM, Pirapora - MG. 
positive RT-PCR test, evolving with persistent cough, progressive dyspnea and desaturation. During the course of the condition, he presented fever, chest pain in the mediastinal region, hyposmia and hypogeusia. The therapeutic approach required hospitalization, low-flow oxygen therapy, systemic corticosteroids, intravenous antibiotic therapy and respiratory support, with clinical improvement and discharge after 10 days of hospitalization. Chest X-ray on the ninth day of symptoms showed interstitial-alveolar parenchymal opacities, and Computed Tomography of the Pulmonary Arteries, performed after 25 days of symptoms, showed extensive Pulmonary Thromboembolism (PTE). Final considerations: The report reinforces the importance of recognizing the characteristics, evolution and cardiorespiratory complications of the disease, understanding that the aspects of imaging exams are heterogeneous among those affected. In this way, perform the best assessment and conduct.

Key words: COVID-19, Computed tomography, Pulmonary embolism, Radiography thoracic.

\section{RESUMEN}

Objetivo: Informar el caso de un paciente diagnosticado de COVID-19, con cambios de imagen típicos y evolución a tromboembolismo pulmonar, relacionando los principales signos y síntomas con cambios en las pruebas de imagen, así como las principales repercusiones cardiorrespiratorias. Detalles del caso: Paciente femenina de 54 años, hipertensa, vacunada con la primera dosis de la vacuna AstraZenecaß frente a SARS CoV2, presentó cuadro gripal y prueba RT-PCR positiva, evolucionando con tos persistente, disnea progresiva y desaturación. Durante el curso del cuadro presentó fiebre, dolortorácico en la región mediastínica, hiposmia e hipogeusia. El abordaje terapéutico requirió hospitalización, oxigenoterapia de bajo flujo, corticoides sistémicos, antibioterapia intravenosa y soporte respiratorio, con mejoría clínica y alta a los 10 días de internación. La radiografía de tórax al noveno día de síntomas mostró opacidades parenquimatosas intersticial-alveolares y la tomografía computarizada de arterias pulmonares, realizada a los 25 días de síntomas, mostró una extensa Embolia Pulmonar (EP). Consideraciones finales: El informe refuerza la importancia de reconocer las características, evolución y complicaciones cardiorrespiratorias de la enfermedad, entendiendo que los aspectos de los exámenes de imagen son heterogéneos entre los af ectados. De esta forma, realice la mejor evaluación y conducta.

Palabras clave: COVID-19, Tomografía computadorizada, Embolia pulmonar, Radiografía torácica.

\section{INTRODUÇÃO}

A pandemia provocada pelo COVID-19 resultou em uma grande repercussão mundial em 2020. O coronavírus causador da Síndrome Respiratória Aguda Grave (SARS-CoV) já era conhecido pela pandemia iniciada na Ásia em 2002/2003. Porém uma variação surgiu em dezembro de 2019 na cidade de Wuhan, província de Hubei, na China, sendo denominada de SARS-CoV-2 (BRITO WGF e SILVA JPDO, 2020). A COVID-19 tem se mostrado altamente transmissível e sua disseminação ocorre através das secreções respiratórias e do contato com superfícies contaminadas (CHATE RC, et al., 2020).

O quadro clínico da COVID-19 é semelhante aos sintomas gripais típicos de outras infecções virais respiratórias, sendo $80 \%$ quadros sintomáticos leves, com febre, tosse geralmente seca, cansaço, e, em casos graves (5\% dos pacientes), pode surgir dispneia, sangramento pulmonar, pneumonia, insuficiência respiratória, linfopenia grave e insuficiência renal, podendo evoluir para Síndrome Respiratória Aguda Grave (SRAG) e óbito, principalmente, em indivíduos idosos e portadores de comorbidades como Hipertensão Arterial Sistêmica (HAS), Diabetes Mellitus (DM), obesidade, câncer e doenças cardiovasculares, se tornando os principais alvos da alta letalidade do vírus (STRABELLI, TMV e UIP DE, 2020; MUNIYAPPA R e GUBBI $S, 2020)$.

Para confirmação diagnóstica do vírus em paciente sintomáticos, coleta-se amostras de secreção respiratória por meio de um swab nasal, seguindo com a pesquisa do RNA viral mediante Reação em Cadeia da Polimerase via Transcriptase Reversa (RT-PCR), a qual é padrão-ouro para tal infecção e que possui

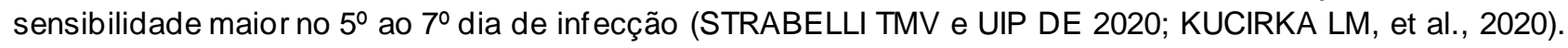

Além dele, há a sorologia que identifica anticorpos específicos produzidos pela resposta imunológica ao vírus, sendo os anticorpos $\lg M$ detectados do $5^{\circ}$ dia de infecção até 2 a 3 semanas da doença e os $\lg G$ 
aparecendo aproximadamente após 14 dias. Porfim, há testes rápidos de antígeno que detectam o vírus em amostras do trato respiratório superior na fase aguda e de anticorpo, que utilizam gota de sangue da polpa digital para detecção da doença (KUCIRKA LM, et al., 2020; SETHURAMAN N, et al., 2020).

As alterações laboratoriais são inespecíficas, sendo encontrado principalmente o aumento da Proteína $C$ Reativa (PCR), da Velocidade de Hemossedimentação (VHS), do Lactato Desidrogenase (LDH), da ferritina, da Alanina Aminotransferase (ALT), da Aspartato Aminotransferase (AST) e do D-dímero, a diminuição da albumina, linfopenia e trombocitopenia leve (LEVI M, et al., 2020). Já nos exames de imagem, podem-se encontrar infiltrados bilaterais na radiografia de tórax e opacidades em vidro fosco periféricas difusas na Tomografia Computadorizada (TC) do tórax. As complicações mais comuns são pneumonia, SRAG, lesão hepática e renal aguda, lesão cardíaca, disritmias, miocardite, coagulopatia pró-trombótica, manifestações neurológicas, doença cerebrovascular aguda e choque (LONG B, et al., 2020; MAO R, et al., 2020; RODRIGUEZ-MORALES AJ, et al., 2020).

O objetivo deste artigo foi relatar o caso de uma paciente diagnosticada com COVID -19, com alterações típicas de imagem e com evolução à tromboembolia pulmonar após alta hospitalar, destacando-se a importância de monitorar os sinais e sintomas do paciente e atentar-se para as possíveis complicações relacionadas.

\section{DETALHAMENTO DO CASO}

Paciente do sexo feminino com 54 anos, previamente hipertensa em uso de Enalapril $10 \mathrm{mg}$ duas vezes ao dia, referia sintomas gripais, tendo teste RT-PCR positivo para pesquisa de COVID-19 no mesmo dia, sendo que havia tido contato com outras pessoas inf ectadas. Após cinco dias, evoluiu com piora clínica, com tosse persistente, dispneia progressiva e dessaturação. Avaliada no Pronto-Socorro no nono dia de sintomas e optado por internação em isolamento. Na evolução do quadro, apresentou também febre, dor torácica em região mediastinal, fraqueza em membros inferiores, hiposmia e hipogeusia. No mês anterior, havia sido vacinada com a primeira dose da vacina AstraZeneca ${ }^{\circledR}$ contra o SARS-CoV2.

No dia seguinte, foi internada em hospital no norte de Minas Gerais devido SRAG/Covid-19. Durante a internação, a paciente necessitou de oxigenioterapia suplementar de baixo fluxo, recebeu corticoide sistêmico, antibioticoterapia endovenosa e suporte respiratório, evoluindo com melhora clínica com possibilidade de desmame de oxigênio, sendo desligado no outro dia pela manhã.

Ao exame físico, estava alerta, orientada, corada, hidratada. Aparelho Cardiovascular: Pressão arterial $125 / 80 \mathrm{mmHg}$, frequência cardíaca $90 \mathrm{bpm}$, ritmo cardíaco regular em dois tempos, bulhas normofonéticas e normorrítmicas, pulsos cheios. Aparelho respiratório: sons respiratórios fisiológicos, reduzidos em bases pulmonares, saturação de oxigênio $96 \%$ em ar ambiente, eupneica, frequência respiratória 20 irpm. Aparelho digestório: normotenso e indolor. Sem edemas e panturrilhas livres.

Nos exames laboratoriais, apresentou hemoglobina $13 \mathrm{~g} / \mathrm{dL}$, leucócitos 11700 células $/ \mathrm{mm}^{3}$, plaquetas

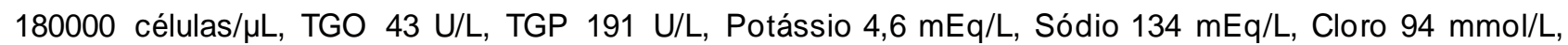
Magnésio $1,8 \mathrm{mg} / \mathrm{dL}$, Cálcio $8,5 \mathrm{mg} / \mathrm{dL}$, Lactato desidrogenase (LDH) $426 \mathrm{UI} / \mathrm{L}$, lactato 20,1 , Creatinina 0,4 $\mathrm{mg} / \mathrm{dL}$, glicose $130 \mathrm{~g} / \mathrm{dL}$, Proteína C-reativa (PCR) negativa, pH 7,3, Pressão parcial de gás carbônico (PCO2) $30 \mathrm{mmHg}$, Pressão parcial de oxigênio (PO2) $80 \mathrm{mmHg}$, saturação de oxigênio (SatO2) $86 \%$, bicarbonato (HCO3-) $19 \mathrm{mEq} / \mathrm{L}$. Ao nono dia, realizou-se Radiografia de tórax em incidência póstero-anterior (PA) e perfil evidenciando opacidades interstício-alveolares bilaterais (Figura 1).

Após 10 dias de internação, possuía condições clínicas para alta hospitalar, mantendo apenas o quadro de tosse. Prescrito Rivaroxabana (Xarelto $\left.\AA^{\circledR}\right) 10 \mathrm{mg} /$ dia profilática por 30 dias, devido insuficiência venosa crônica, Acebrofilina e Levofloxacino. Substituído o Enalapril pelo Losartana devido a tosse. Após 25 dias de início dos sintomas, realizou-se Angiotomografia computadorizada de Artérias Pulmonares evidenciando Tromboembolia Pulmonar (TEP), sendo mantido a Rivaroxabana por mais três meses (Figura 2). 
Figura 1 - Radiografia de tórax em PA e perfil.
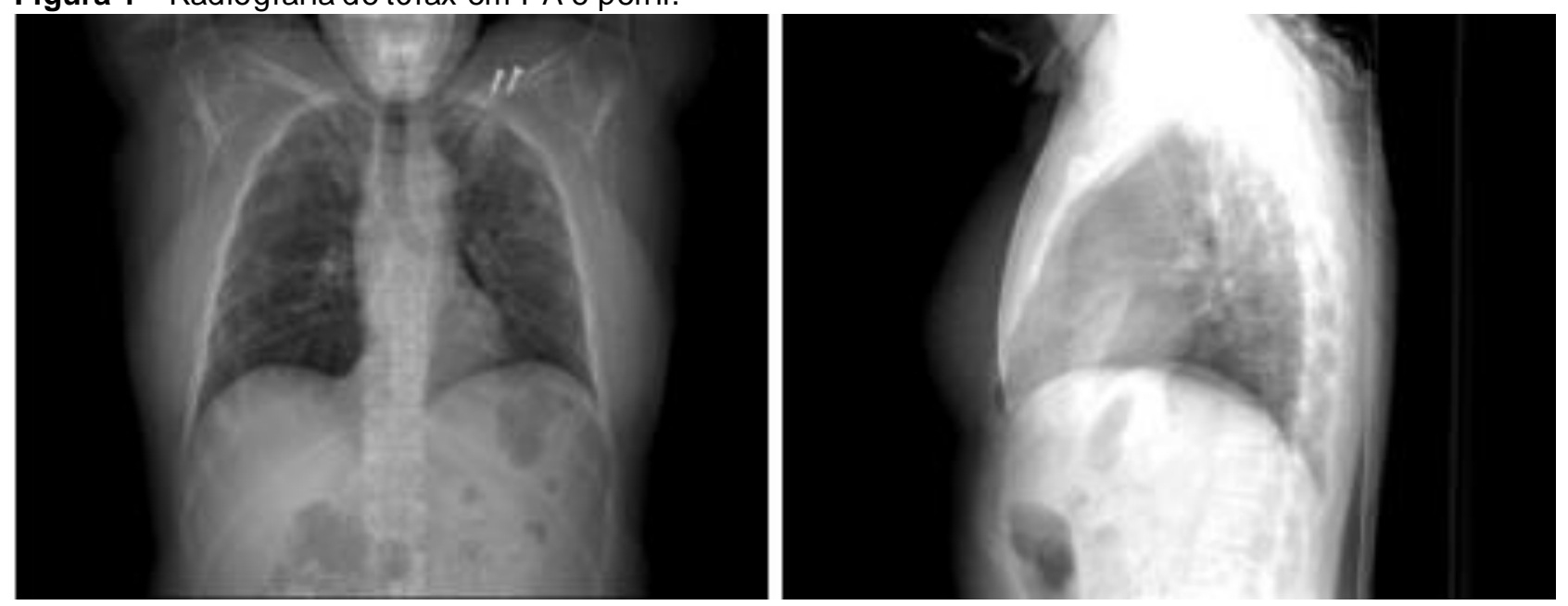

Legenda: Opacidades parenquimatosas de padrão interstício-alveolar esparsas em ambos os pulmões, com distribuição predominantemente periférica e peribroncovascular, aorta alongada, índice cardiotorácico dentro dos limites da normalidade, seios costofrênicos livres, discretas alterações degenerativas na coluna torácica, parafusos metálicos de fixação no terço médio da clavícula esquerda. Fonte: Leite MC, et al., 2021.

Figura 2 - Angiotomografia computadorizada de Artérias Pulmonares

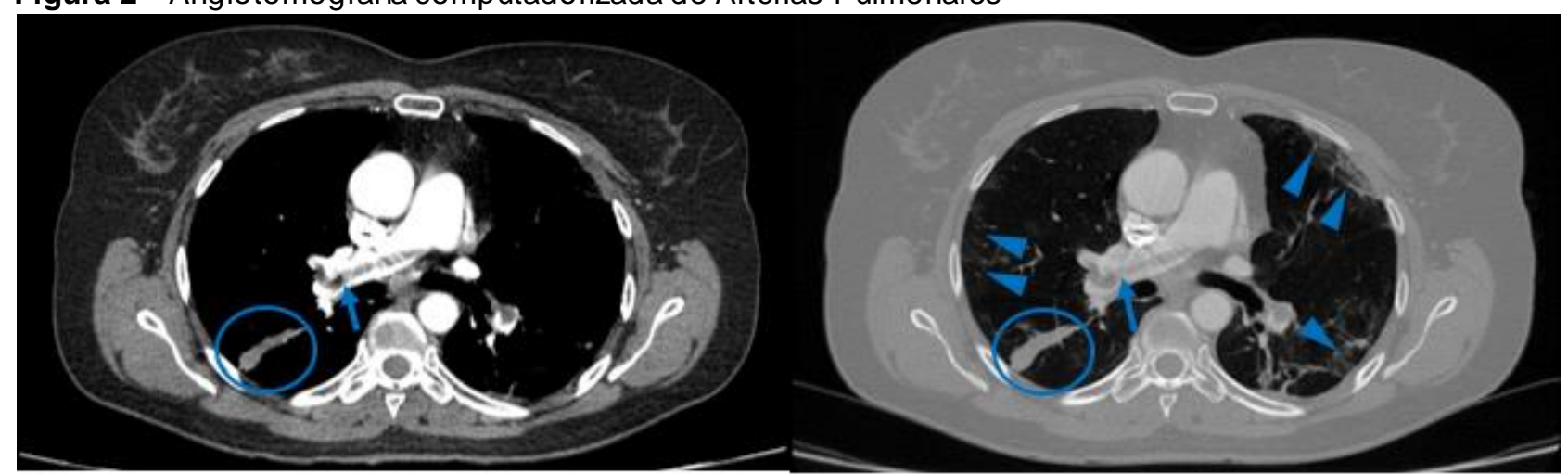

A

B

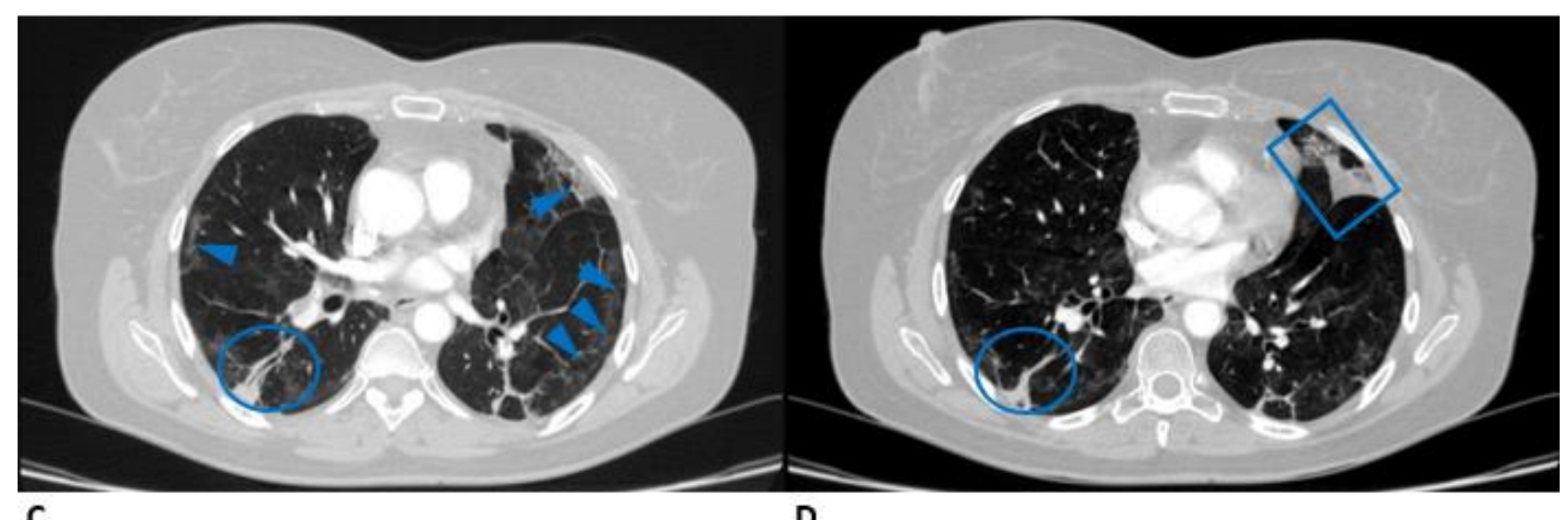

C

D

Legenda: Tromboembolia Pulmonar (TEP) extensa na bifurcação do tronco pulmonar (seta - Imagens A e B), com extensão lobar e segmentar bilateral, acometendo lobos superior esquerdo (língula), médio e lobos inferiores, com sinais de sobrecarga de câmaras direitas. Opacidades pulmonares em "vidro fosco" (ponta de seta - Imagens B e C) associadas a linhas intralobulares, espessamento septal e linhas subpleurais, de predomínio periférico, bandas parenquimatosas cicatriciais nos lobos superiores (retângulo - imagem D) e atelectasias laminares esparsas (círculo - Imagens A, B, C e D). Fonte: Leite MC, et al., 2021. 


\section{DISCUSSÃo}

A pandemia do novo coronavírus mudou a perspectiva médica quanto à elucidação de diagnósticos e escolha de condutas especializadas. A presença de uma entidade nova com potencial risco letal sujeitou ao mundo frentes de incertezas que af etam todos os serviços de assistência à saúde. Depois de um ano sof rendo com as consequências dessa enfermidade, nem toda a ciência tem conseguido responder às incógnitas que ela vem apresentando. Sua abrangência de apresentações e possíveis complicações fizeram com que as propedêuticas mais avançadas compuseram seu manejo, destacando os diagnósticos por imagem da radiografia torácica e tomografia computadorizada, exames protagonistas nos protocolos mais atuais (ARAUJO-FILHO JAB, et al., 2020).

Devido ao aumento da necessidade dos recursos da radiologia, o Colégio Brasileiro de Radiologia estabeleceu recomendações de uso de métodos de imagem para casos suspeitos de COVID-19, determinando que a TC não deve ser utilizada como rastreio ou para o diagnóstico inicial por imagem, sendo reservada para casos graves e situações específicas. Para casos leves e moderados, os princip ais protocolos asseguram a radiografia de tórax como método propedêutico inicial para investigação das complicações pulmonares (PRADO GLM e BARJUD MB, 2020).

\section{Radiografia de Tórax}

A radiografia de tórax é o exame de imagem mais simples e acessível para se submeter pacientes com suspeita de infeção pelo SARS-CoV2. É útil tanto para investigação complementar diagnóstica quanto para avaliar a progressão da doença e suas possíveis complicações e monitoração dos pacientes internados (TORRES PPT, et al., 2020). De acordo com o American College of Radiology, máquinas de radiografia portáteis deveriam ser implementadas nos departamentos responsáveis pelo tratamento dos pacientes com a COVID-19, a fim de facilitar o acompanhamento e a realização do procedimento quando análises do comprometimento pulmonar são necessárias (CELLINA M, et al., 2020).

Mesmo tendo fácil execução, seu resultado é operador-dependente e, além disso, confere baixa sensibilidade em fase leve ou inicial da doença, variando em torno de $30-69 \%$, podendo apresentar exames sem alterações nesta fase, dif erentemente de uma TC que, por possuir maior sensibilidade, consegue captar o comprometimento ocasionado pelo vírus mesmo nos primeiros dias de sintomas (MEIRELLES GSP, 2020).. É interessante ressaltar que indivíduos assintomáticos podem vir a apresentar alterações pulmonares radiológicas apesar da ausência dos sintomas clínicos, todavia com menor comprometimento e predomínio de opacidades e vidro fosco, quando comparados aos indivíduos sintomáticos, os quais possuem acometimento pulmonar mais extenso (CHATE RC, et al., 2020).

As alterações radiológicas são mais bem visualizadas no período de 10-12 dias de sintomas da doença e ao exame radiográfico, os achados mais comuns são opacidades de baixa densidade, as quais estão demonstradas no quadro relatado acima, com predomínio basal periférico que podem evoluir rapidamente para consolidação difusa dentro de 1 a 3 semanas do início dos sintomas (MEIRELLES GSP, 2020).

Ainda segundo Meirelles GSP (2020), o surgimento de derrame pleural não é tão comum e, geralmente, configura um quadro mais grave desta af ecção. Além disso, cavitação pulmonar e pneumotórax também são achados poucos esperados, sendo este último mais presente em pacientes que desenvolvem a SRAG em decorrência da lesão do parênquima pulmonar e presença de necrose.

Ademais, para melhor avaliação e prognóstico do paciente, os achados radiográficos acompanham a evolução da doença, sendo então estabelecidos de acordo com a fase em que a doença está: fase l/fase viral: radiografia sem alterações ou com presença de opacidades pulmonares difusas de baixa visualização; fase IIA e IIB/fase inflamatória: radiografia com discretas opacificações e/ou opacificações mais conspícuas com melhor visualização em IIB, padrão de distribuição desde áreas focais periféricas até mais extensas; fase III: extensas opacificações pulmonares (PRADO GLM e BARJUD MB, 2020).

\section{Tomografia Computadorizada}

Nos casos de COVID-19 avaliados pela TC de tórax sem contraste, vê-se as manifestações radiológicas provenientes das principais alterações histopatológicas que, segundo Leão MLP, et al. (2020), são as de dano 
alveolar difuso exsudativo, que leva a uma lesão pulmonar aguda e extensa. Conforme discutido por Brito SBP, et al. (2020), a patogênese da doença envolve edema intersticial, congestão capilar e intensa dilatação dos espaços alveolares, com atipia, hiperplasia e perda de pneumócitos do tipo 2. Como percebido por Carvalho FRS, et al. (2020), tal fato permite que o grande exsudato inflamatório preencha, parcial ou completamente, os alvéolos pulmonares de modo que gere colabamento e comprometimento das trocas gasosas, a base da insuficiência respiratória nos pacientes.

A literatura acerca dos achados tomográficos referentes ao COVID-19 mostra alguns padrões de achados tipicamente encontrados na pneumonia viral pelo SARS-COV-2, entretanto, como descrito por Araujo-Filho JAB, et al. (2020), tais achados não são específicos desta pneumonia, podendo ser encontrados em outras doenças.

O padrão mais encontrado é o de vidro fosco, que segundo Prado GLM e Barjud MB (2020), trata-se de uma opacificação que não obscurece vasos, sendo um preenchimento parcial dos alvéolos pulmonares por restos celulares inflamatórios, ou mesmo espessamento intersticial. Tal padrão pode não ser encontrado, ou estar presente apenas em áreas focais, predominantemente periféricas e basais, na fase viral da doença; progredindo, posteriormente na fase inflamatória, para maior acometimento do parênquima pulmo nar, comumente periférico, bilateral e multifocal. Ademais, é frequente encontrar o padrão de pavimentação em mosaico na fase inflamatória da doença, em um estágio posterior ao encontro do padrão de vidro fosco.

Segundo Rosa MEE, et al. (2020), a pavimentação em mosaico é o espessamento de septos intra e interlobulares se sobrepondo nas opacidades em vidro fosco. A evolução dos achados para o padrão de consolidação pode ocorrer em fases mais tardias da doença, evidenciando aumento da densidade pulmonar que obscurece o contorno dos vasos e de estruturas brônquicas (SILVA LS, et al., 2021).

Como percebido por Farias LPG, et al. (2020), achados menos comuns nesta infecção são as opacidades reticulares, tratando-se de padrão de acometimento intersticial, do tecido conectivo que sustenta 0 parênquima pulmonar; linhas subpleurais, que podem indicar, inespecificamente, presença de atelectasia e, quando juntamente a espessamento pleural, fibrose; e sinal do halo invertido, visualizado como uma opacidade focal em vidro fosco que é circundada por consolidação, ou seja, a densidade é maior na periferia e menor no centro da lesão.

Faz-se necessário frisar que tais achados da TC de tórax na infecção pelo SARS-CoV2 são encontrados, majoritariamente, nas regiões periféricas e posteriores dos lobos pulmonares, sendo o acometimento multilobar e frequentemente bilateral (ROSA MEE, et al., 2020). Ainda, segundo Farias LPG, et al. (2020), encontra-se opacidades lineares e retráteis nas fases mais tardias da infecção, além de poderem persistir achados focais de opacidades em vidro fosco e diminutos consolidações em alguns casos.

A manifestação em outros sistemas orgânicos tem ganhado destaque na fisiopatologia da doença, principalmente aquelas relacionadas a coagulopatias, como no caso relatado, a presença de TEP, evento trombótico mais comum (GOMES TCA, et al., 2020). A fisiopatologia que envolve tal complicação à infecção por SARS-CoV2 ainda não está totalmente elucidada, contudo, pressupõe-se que esteja relacionada ao estado de hipercoagulação estimulada pela ação viral sobre a geração de trombina e diminuição dos anticoagulantes naturais. Estudos recentes demonstram que níveis de dímero-D maiores que $1.000 \mathrm{ng} / \mathrm{ml}$ em pacientes com COVID-19 indicam um pior prognóstico e alta mortalidade (CARVALHO ACS, et al., 2020).

Recentemente, a sigla MicroCLOTS (síndrome trombo inflamatória obstrutiva dos vasos pulmonares microvascular COVID-19) foi proposta para caracterizar a microangiopatia trombótica pulmonar causada pelo novo coronavírus (FRANCO-MORENO A, et al., 2020).

Um estudo feito em Madri, pela Sección Radiología de Urgencias do Hospital Universitário, incluiu 492 angiotomografias pulmonares para estudo das imagens, em que $342(69,9 \%)$ dos pacientes estavam com COVID-19 e $147(30,1 \%)$ dos pacientes não tinham a infecção. Como resultados, notou-se a prevalência de TEP de 26\% no grupo COVID-19 positivo e 16,3\% no grupo negativo. Não houve diferenças significativas no nível de dímeros-D ou na localização da lesão dos ramos arteriais entre os dois grupos (CHAMORRO EM, et al., 2021). 
A angiotomografia é o padrão-ouro para avaliar presença de TEP nesses pacientes, evidenciando, na vigência da doença, a presença de falhas de enchimento dos ramos arteriais, caracterizando a obstrução trombótica do fluxo. Ademais, o corte axial em janela conclui a avaliação do parênquima pulmonar, no qual achados consistentes de pneumonia pelo coronavírus podem ser evidenciados, como múltiplas opacidades em vidro fosco associadas a espessamento de septos interlobulares (JASINOWODOLINSKI D, et al., 2020). No caso da paciente em relato, observou-se falhas de enchimento vascular na bifurcação do tronco pulmonar nas artérias principais direita e esquerda. $O$ estudo das imagens do parênquima evidenciou processo infeccioso pneumônico recente. À luz desses achados, juntamente com a história de RT-PCR positivo para o SARS-CoV2, é possível concluir a complicação típica de TEP por COVID-19.

No caso relatado, a paciente apresenta na angiotomografia aumento das câmaras cardíacas direitas, achado que sugere sobrecarga. Conforme Cabrita IZ (2014), o TEP agudo está associado à alta morbidade e mortalidade. A principal causa dos óbitos que envolvem essa patologia é a disfunção do $V$ entrículo Direito (VD), e a sobrevivência dos pacientes depende da rápida recanalização do ramo comprometido e da consequente redução da resistência ao fluxo de ejeção. Essa sobrecarga direita é resultante do aumento da resistência imposta por essas câmeras devido à obstrução do fluxo sanguíneo no sistem a pulmonar. Segundo Beraldo GL, et al. (2020), em casos de pacientes que apresentarem piora abrupta da dispneia e do padrão respiratório, é de extrema importância associar a suspeita de TEP ao quadro infeccioso de COVID -19, uma vez que a sobreposição de achados clínicos e laboratoriais dificulta o correto diagnóstico e impacta na morbimortalidade.

Diante da pandemia do COVID-19, é importante reconhecer que as características e evolução da doença são heterogêneas. Assim, os aspectos radiológicos pulmonares são distintos, de acordo com o exame utilizado e o tempo dos sintomas. A radiografia, apesar de ser acessível e simples, tem baixa sensibilidade nas fases iniciais da doença, podendo se mostrar inalterada a princípio. A TC, embora seja reservada para casos delicados e específicos, possui maior sensibilidade, sendo o exame de escolha para avaliar a presença de TEP. O objetivo do trabalho é relacionar o caso clínico citado com as principais alterações radiológicas em pacientes infectados e as manifestações cardiorrespiratórias mais comuns. Compreender as utilidades e limitações dos exames radiológicos é fundamental para uma propedêutica eficaz.

\section{REFERÊNCIAS}

1. ARAUJO-FILHO JAB, et al. Pneumonia por COVID-19: qual o papel da imagem no diagnóstico?. Jornal Brasileiro de Pneumologia, 2020;46 (02):1-2.

2. BERALDO GL, et al. Pneumonia pelo novo coronavírus e tromboembolismo pulmonar agudo: casualidade ou causalidade?. Einstein (São Paulo), 2020;18:1-2.

3. BERTOLAZZI P, et al. A importância da Tomografia Computadorizada no diagnóstico da COVID-19/The importance of Computed Tomography in diagnosis of COVID-19. Arquivos Médicos dos Hospitais e da Faculdade de Ciências Médicas da Santa Casa de São Paulo, 2020;65 (01):1-4.

4. BRITO SBP, et al. Mecanismos imunopatológicos envolvidos na infecção por SARS-CoV-2. Jornal Brasileiro de Patologia e Medicina Laboratorial, 2020;56:1-10.

5. BRITO WGF, SILVA JPDO. Impactos neuropatológicos do COVID-19. Brazilian Journal of Health Review. 2020;3(3), 4227-4235.

6. CABRITA IZ. Imagiologia cardíaca no tromboembolismo pulmonar: avaliação da disfunção ventricular direita por Doppler tecidular. Revista Portuguesa de Cardiologia, 2014;33(10):597-598.

7. CARVALHO ACS, et al. Moduladores de coagulação alterados comprometem os pa cientes infectados com COVID19. Brazilian Journal of Health Review, 2020;3(5):11624-11644.

8. CARVALHO FRS, et al. Fisiopatologia da COVID-19: repercussões sistêmicas. Unesc em Revista, 2020; 4(02):170184.

9. CELLINA M, et al. COVID-19 pneumonia-ultrasound, radiographic, and computed tomography findings: a comprehensive pictorial essay. Emergency Radiology, 2021;28(03):519-526.

10. CHAMORRO EM, etal. Tromboem bolismo pulmonar em pacientes com COVID-19: estudo de prevalência em hospital terciário. Radiologia, 2021;63(01):13-21.

11. CHATE RC, et al. Presentation of pulmonary infection on CT in COVID-19: initial experience in brazil. Jornal Brasileiro de Pneumologia, Brasília, 2020;46(02):1-4.

12. FARIAS LPG, et al. Alterações tomográficas torácicas em pacientes sintomáticos respiratórios com a COVID-19. Radiologia Brasileira, 2020;53(04):255-261. 
13. FRANCO-MORENO A, et al. Tromboembolismo pulmonar y COVID-19: un cambio de paradigma. Revista clínica española, 2020;220(07):459.

14. GOMES TCA, et al. Eventos tromboembólicos em pacientes com COVID-19: revisão sistemática. Hematology, Transfusion and Cell Therapy, 2020; 42(2):533.

15. JASINOWODOLINSKI D, et al. Pneumonia por COVID-19: um fator de risco para tromboembolismo pulmonar? . Jomal Brasileiro de Pneumologia, 2020;46(04):1-2.

16. KUCIRKA LM, et al. Variation in false-negative rate of reverse transcriptase polymerase chain reaction-basedSARSCoV-2 tests by time since exposure. Annals of internal medicine, 2020;173(4):262-267.

17. LEÃO MLP, et al. Alterações histopatológicas em portadores do novo coronavírus (SARS-CoV-2). Análise da síndrome inflamatória multissistêmica em crianças (MIS-C) associada à infecção pelo SARS-CoV2, 2020; 2178(54):2091.

18. LEVI M, et al. Coagulation abnormalities and thrombosis in patients with COVID -19. The Lancet Haematology, 2020; $7(6): 438-440$.

19. LONG B, et al. Cardiovascular complications in COVID-19. The American journal of emergency medicine, 2020;38(7): 1504-1507.

20. MAO R, et al. Manifestations and prognosis of gastrointestinal and liver involvement in patients with COVID-19: a systematic review and meta-analysis. The lancet Gastroenterology \& hepatology, 2020;5(7):667-678.

21. MEIRELLES GSP. COVID-19: uma breve atualização para radiologistas. Radiologia Brasileira, 2020;53(5):320 -328.

22. MUNIYAPPA R, GUBBI S. COVID-19 pandemic, coronaviruses, and diabetes mellitus. American Journal of Physiology-Endocrinology and Metabolism, 2020;318(5):736-741.

23. PRADO GLM, BARJUD MB. Radiologia em COVID 19: Fisiopatologia e aspectos da imagem nas diferentes fases clínicas da doença. Revista da FAESF, 2020;4:11-15.

24. RODRIGUEZ-MORALES AJ, et al. Clinical, laboratory and imaging features of COVID-19: A systematic review and meta-analysis. Travel medicine and infectious disease, 2020;34.

25. ROSA MEE, et al. Achados da COVID-19 identificados na tomografia computadorizada de tórax: ensaio pictórico. Einstein (São Paulo), 2020;18:1-6.

26. SETHURAMAN N, et al. Interpreting diagnostic tests for SARS-CoV-2. Jama, 2020;323(22):2249-2251.

27. SILVA LS, et al. Exames de imagem como método complementar para o diagnóstico da COVID-19:revisão integrativa de literatura. Revista de Medicina da UFC, 2021;61(01):1-8.

28. STRABELLI TMV, UIP DE. COVID-19 e o Coração. Arquivos Brasileiros de Cardiologia. 2020;114(4):598-600.

29. TORRES PPT, et al. COVID-19: radiografia de tórax na predição de desfecho clínico. Jornal Brasileiro de Pneumologia, 2020;46(05):1-2.

30. VALENTIN MV, et al. Aspectos radiológicos em paciente com covid-19: um relato de caso. Revista Interdisciplinar de Saúde e Educação, 2020; 1(02):249-259. 